\title{
HYDROTHERMAL SYNTHESIS OF NOVEL CERIUM(III) AND MANGANSE(II) ACTIVATED CALCIUM HYDROGENPHOSPHATE ANHYDRATE PHOSPHORS EMITTING BY BLACK LIGHT IRRADIATION
}

\author{
Takeshi TOYAMA*, Masato HASHIMOTO, Takahiko KOJIMA and Tamotsu YASUE \\ (*Corresponding author: ttoyama@chem.cst.nihon-u.ac.jp) \\ Department of Materials and Applied Chemistry, Faculty of Science and Engineering, NIHON University, \\ 1-8 Kanda-Surugadai, Chiyoda, Tokyo 101-8308 Japan.
}

Keywords: Calcium hydrogenphosphate anhydrate, Phosphor, Amorphous calcium phosphate, Hydrothermal synthesis, Black light

\begin{abstract}
The present work was investigated about hydrothermal synthesis of $\mathrm{Ce}^{3+}$ and $\mathrm{Mn}^{2+}$ activated calcium hydrogenphosphate anhydrate $\left(\mathrm{CaHPO}_{4}: \mathrm{Ce}^{3+}, \mathrm{Mn}^{2+}\right)$ phosphors. $\mathrm{CaHPO}_{4}: \mathrm{Ce}^{3+}, \mathrm{Mn}^{2+}$ was a novel unprecedented phosphor, which was synthesized by hydrothermal treatment of dipping amorphous calcium phosphate (ACP) in formic acid aqueous solution. The emission intensity of the $\mathrm{CaHPO}_{4}: \mathrm{Ce}^{3+}, \mathrm{Mn}^{2+}$ phosphor was affected remarkably by synthetic conditions such as $\mathrm{Ce} / \mathrm{Ca}$ and $\mathrm{Mn} / \mathrm{Ca}$ atomic ratio, concentration of formic acid, temperature and aging time. The optimum conditions for the synthesis of $\mathrm{CaHPO}_{4}: \mathrm{Ce}^{3+}, \mathrm{Mn}^{2+}$ phosphor were follows; $\mathrm{Ce} / \mathrm{Ca}$ atomic ratio, $0.01 ; \mathrm{Mn} / \mathrm{Ca}$ atomic ratio, 0.02 ; concentration of formic acid, $1.0 \mathrm{~mol} \cdot \mathrm{dm}^{-3}$; hydrothermal temperature, $170^{\circ} \mathrm{C}$; retention time, $0 \mathrm{~h}$.
\end{abstract}

(Received July 14, 2004; Accepted August 24, 2004)

\section{INTRODUCTION}

Black light is a lamp which emit near-UV (ultraviolet) of wavelengths at $300-400 \mathrm{~nm}$, and is widely used for traffic safety measures, illuminations in cities, indoor interiors, and so on. So a phosphor which is emitted by black light irradiation has attracted attention. On the other hand, calcium phosphate salt host as phosphor are known $\mathrm{Sb}^{3+}, \mathrm{Mn}^{2+}$ activated apatite phosphor ${ }^{1)}, \mathrm{Ce}^{3+}, \mathrm{Mn}^{2+}$ activated apatite phosphor ${ }^{2)}$ with emitting by the UV of $254 \mathrm{~nm}$. And there are also known $\mathrm{Ce}^{3+}, \mathrm{Mn}^{2+}$ activated tricalcium phosphate ${ }^{3)}$, which is emitting by the black light irradiation with around $360 \mathrm{~nm}$. Generally, a phosphor is prepared by sintering process with high temperature above $1000^{\circ} \mathrm{C}$ for several time ${ }^{4)}$. Because of this, there are no reports on the preparation of phosphor of unstable calcium hydrogenphosphate anhydrate $\left(\mathrm{CaHPO}_{4}, \mathrm{DCPA}\right)$ host, since it decomposed under the high temperature.

The authors have been conducting a series of studies on synthesis of amorphous calcium phosphate $\left(\mathrm{Ca}_{3}\left(\mathrm{PO}_{4}\right)_{2} \cdot n \mathrm{H}_{2} \mathrm{O}, \mathrm{ACP}\right)$ and its characteristics ${ }^{5)-24)}$. The ACP as a precursor of calcium phosphate salts is useful as a starting material of functional materials. And, it is expected to decrease with the produced temperature of phosphor by using ACP as starting materials $^{17,24)}$.

DCPA is well known as a starting material of an apatite phosphor for general lamp phosphor, and it is easily obtained to dehydrate calcium hydrogenphosphate dihydrate $\left(\mathrm{CaHPO}_{4} \cdot 2 \mathrm{H}_{2} \mathrm{O}\right.$, DCPD) by heating in humid air process at $135^{\circ} \mathrm{C}^{25}$. On the other hand, the authors have already reported that ACP crystallized into DCPA by hydrothermal treatment in formic acid solution.

Therefore, it is suggested that preparation of a novel unprecedented phosphor is possible with DCPA host, by hydrothermal treatment of active ACP and $\mathrm{Ce}^{3+}, \mathrm{Mn}^{2+}$ activation mixture in formic acid solution.

The present work was investigated about hydrothermal synthetic condition of novel cerium(III) and manganese(II) activated DCPA phosphor from active $\mathrm{ACP}$, and its fluorescent property.

\section{MATERIALS AND METHODS}

\section{MATERIALS}

The ACP $(\mathrm{Ca} / \mathrm{P}$ atomic ratio of 1.50$)$ as a starting material was synthesized by mixing $0.17 \mathrm{~mol} \cdot \mathrm{dm}^{-3}$ calcium nitrate $\left(\mathrm{Ca}\left(\mathrm{NO}_{3}\right)_{2}\right)$ solution with $0.10 \mathrm{~mol} \cdot$ $\mathrm{dm}^{-3}$ diammonium hydrogen phosphate $\left(\left(\mathrm{NH}_{4}\right)_{2} \mathrm{HPO}_{4}\right)$ solution. The synthesized ACP gel was separated by filtering, it was washed with cold aqueous ammonia and acetone. After, the amorphous tricalcium phosphate anhydrate (amorphous- $\left.\mathrm{Ca}_{3}\left(\mathrm{PO}_{4}\right)_{2}, \mathrm{ATCP}\right)$ as raw material of phosphor was obtained by dehydrating $\mathrm{ACP}$ at $300^{\circ} \mathrm{C}$. Furthermore, all reagent were used with KANTO KAGAKU Co.,Ltd.

\section{EXPERIMENTAL METHOD}


Toyama T, Hashimoto M, Kojima T, Yasue T

A mixture ATCP, cerium(III) acetate monohydrate $\left(\mathrm{Ce}\left(\mathrm{CH}_{3} \mathrm{COO}\right)_{3} \cdot \mathrm{H}_{2} \mathrm{O}\right)$ and manganese(II) acetate tetrahydrate $\left(\mathrm{Mn}\left(\mathrm{CH}_{3} \mathrm{COO}\right)_{2} \cdot 4 \mathrm{H}_{2} \mathrm{O}\right)$ was adjusted to initial $\mathrm{Ce} / \mathrm{Ca}, \mathrm{Mn} / \mathrm{Ca}$ atomic ratio of $0-0.08$. The mixture was dipped in formic acid solution on liquid/solid weight ratio 48 in Teflon test tube. Concentration of formic acid solution was $0-2.0 \mathrm{~mol}$ $\mathrm{dm}^{-3}$. After having been stirred for 5 minute with ultrasonic wave dispersion treatment, the suspension was heat at $120-200^{\circ} \mathrm{C}$ for $0-3 \mathrm{~h}$ in an autoclave. Finally, the phosphor was separated from suspension after the reaction and washed with pure water. The experiments were conducted in the autoclave of 120 $\mathrm{cm}^{3}$ volume (TVS-N2 (SUS316), Taiatsu Co.,Ltd.) and packing rate was $50 \mathrm{vol} \%$. This autoclave inside has performed Teflon coating processing and without stirring system.

The phosphor was characterized by means of X-ray powder diffractometry, observation of scanning electron microscopic (SEM-300, Topcon Co.,Ltd.) and chemical analysis. The fluorescent property was measurement of fluorescent spectrometer (RF-1500, Shimadzu Co., Ltd.). Also, the measurement of emission spectrum of phosphor was used by filter (UV35) which shut out excitation light at a wavelength below $350 \mathrm{~nm}$.

Furthermore, the emission intensity of $100 \%$ was a value with $442 \mathrm{~nm}$ emission intensity of commercial calcium tangstate (NakaraiTesque Co.,Ltd.) by the UV irradiated at $254 \mathrm{~nm}$.

\section{RESULTS AND DISSCUSSION}

\section{PREPARATION CONDITION OF CERIUM(III) ACTIVATED DCPA PHOSPHOR}

As a previously report, ACP crystallized into DCPA in formic acid under hydrothermal conditions $^{21)}$. Figure 1 showed the $\mathrm{X}$-ray diffraction pattern of $\mathrm{CaHPO}_{4}: \mathrm{Ce}^{3+}$ phosphor with different $\mathrm{Ce} / \mathrm{Ca}$ atomic ratio. In this study, ACP crystallized into DCPA single phase with $\mathrm{Ce}^{3+}$ addition until the atomic ratio of 0.01 . However, cerium phosphate $\left(\mathrm{CePO}_{4}\right)$ was newly observed at the atomic ratio above 0.01 , and the intensity of X-ray peak $\left(2 \theta=28.7,33.5^{\circ}\right)$ of $\mathrm{CePO}_{4}$ was increased with an increase in the $\mathrm{Ce} / \mathrm{Ca}$ atomic ratio. Also, because of triclinic system, the lattice constant of DCPA was difficult to calculate. Thereupon, the examination was made from a changing of spacing whether the activator is incorporated or not. The spacing of (112) face of DCPA was increased with an increase in the $\mathrm{Ce} / \mathrm{Ca}$ atomic ratio range from 0 to 0.01 . Also, the ionic radius of $\mathrm{Ce}^{3+}(0.107 \mathrm{~nm})$ is larger than that of $\mathrm{Ca}^{2+}$ $(0.099 \mathrm{~nm})$. The results indicate that additive $\mathrm{Ce}^{3+}$ was incorporated to $\mathrm{Ca}^{2+}$ with DCPA crystal structure.

Figure 2 showed the excitation and emission spectrum of $\mathrm{CaHPO}_{4}: \mathrm{Ce}^{3+}$ phosphor. Under conditions of black light irradiation at 300-350 nm, the $\mathrm{Ce}^{3+}$ activated apatite or tricalcium phosphate phosphor were known as emitting in near-UV at
$370-390 \mathrm{~nm}$ which is beyond the range of visible radiation ${ }^{1), 2)}$. The excitation spectrum was observed that $\mathrm{CaHPO}_{4}: \mathrm{Ce}^{3+}$ phosphor was irradiated at the near-UV of $370 \mathrm{~nm}$. Also, the phosphor was emitted by black light irradiation at $320 \mathrm{~nm}$. The emission peak wavelength of phosphor was $370 \mathrm{~nm}$. This

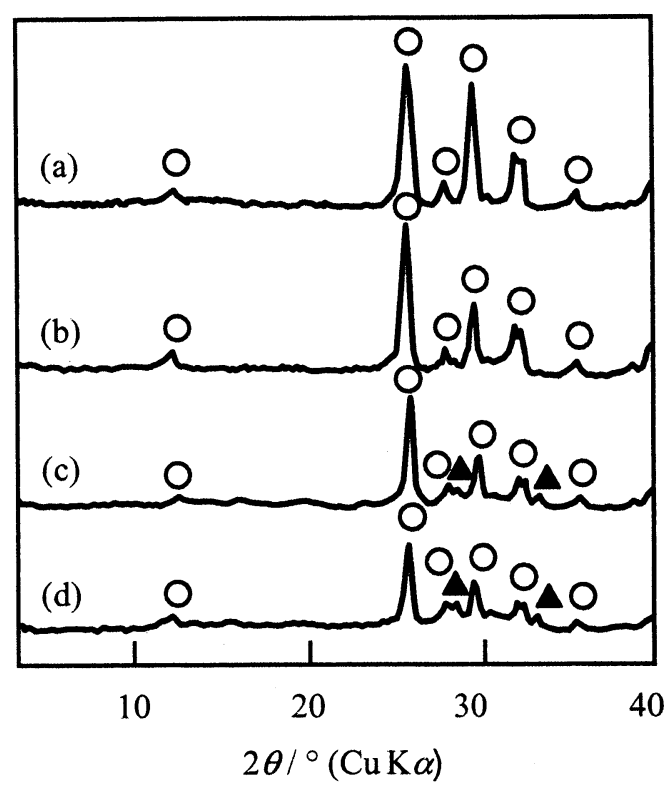

Fig.1 X-ray diffraction pattern of phosphor with different $\mathrm{Ce} / \mathrm{Ca}$ atomic ratio.

Temp.: $170^{\circ} \mathrm{C}$, Retention time: $0 \mathrm{~h}$, Concentration of formic acid: $1.0 \mathrm{~mol} \cdot \mathrm{dm}^{-3}, \mathrm{Ce} / \mathrm{Ca}$ atomic ratio, (a): 0 , (b): $0.01,(\mathrm{c}): 0.02,(\mathrm{~d}): 0.04$

$\mathrm{O}: \mathrm{CaHPO}_{4}, \mathbf{\Lambda}: \mathrm{CePO}_{4}$

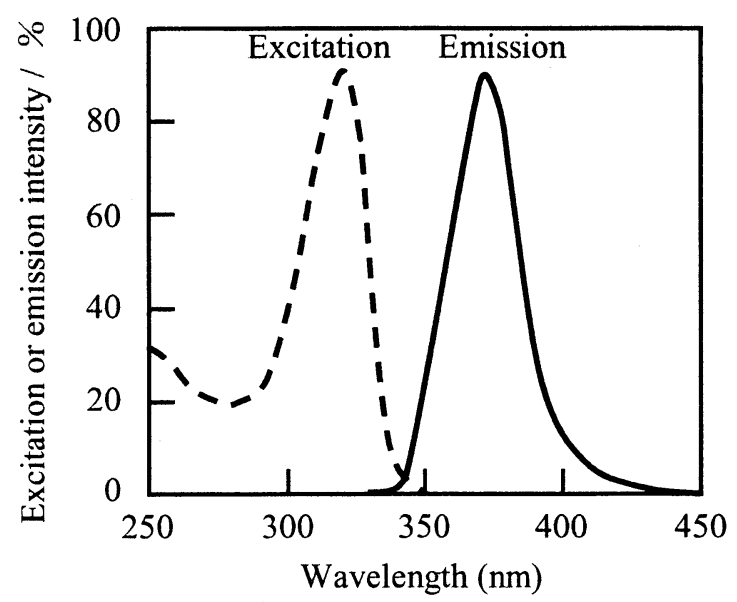

Fig. 2 Excitation and emission spectrum of $\mathrm{CaHPO}_{4}: \mathrm{Ce}^{3+}$ phosphor.

Temp.: $170^{\circ} \mathrm{C}$, Retention time: $0 \mathrm{~h}$, Concentration of formic acid: $1.0 \mathrm{~mol} \cdot \mathrm{dm}^{-3}, \mathrm{Ce} / \mathrm{Ca}$ atomic ratio: 0.01 


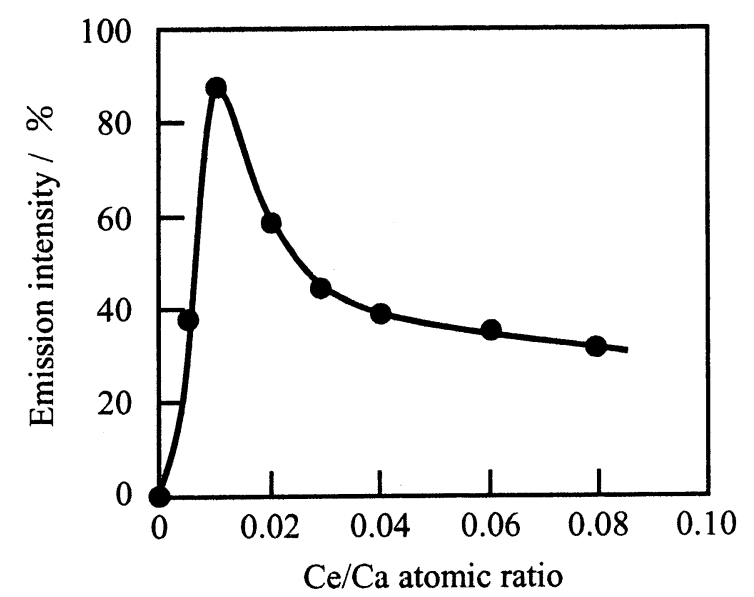

Fig. 3 Effect of $\mathrm{Ce} / \mathrm{Ca}$ atomic ratio on the emission intensity of $\mathrm{CaHPO}_{4}: \mathrm{Ce}^{3+}$ phosphor.

Temp.: $170^{\circ} \mathrm{C}$, Retention time: $0 \mathrm{~h}$, Concentration of formic acid: $1.0 \mathrm{~mol} \cdot \mathrm{dm}^{-3}$, Excitation wavelength: 320 $\mathrm{nm}$, Measuring wavelength: $370 \mathrm{~nm}$

emission spectrum was similar to the spectrum of other phosphors with emitting near-UV of $370 \mathrm{~nm}$.

Figure 3 showed the effect of $\mathrm{Ce} / \mathrm{Ca}$ atomic ratio on the emission intensity of $\mathrm{CaHPO}_{4}: \mathrm{Ce}^{3+}$ phosphor. The emission was not observed the phosphor without $\mathrm{Ce}^{3+}$ activated. However, the emission intensity was increased with an increase in the atomic ratio. Especially, the emission intensity of the phosphor with $\mathrm{Ce} / \mathrm{Ca}$ atomic ratio of 0.01 was showed the maximum $90 \%$. However, the emission intensity was rapidly decreased at $\mathrm{Ce} / \mathrm{Ca}$ atomic ratio above 0.01. This reason is considered that $\mathrm{CePO}_{4}$ which is impurity mixed into phosphor, and concentration quenching.

Figure 4 showed the effect of hydrothermal temperature on synthesis of $\mathrm{CaHPO}_{4}: \mathrm{Ce}^{3+}$ phosphor. When temperature was lower at $120^{\circ} \mathrm{C}(\mathrm{a})$, low crystalline DCPA was observed. Also, as temperature was higher, crystalline of DCPA was improved(b), especially X-ray intensity of DCPA was the greatest at $170^{\circ} \mathrm{C}(\mathrm{c})$. However, as temperature was increased further temperature, hydroxyapatite $\left(\mathrm{Ca}_{10}\left(\mathrm{PO}_{4}\right)_{6}(\mathrm{OH})_{2}, \mathrm{HAp}\right)$ observed.

Therefore, Figure 5 showed the effect of hydrothermal temperature on the emission intensity of $\mathrm{CaHPO}_{4}: \mathrm{Ce}^{3+}$ phosphor. When the X-ray intensity of DCPA was greatest at $170^{\circ} \mathrm{C}$, the emission intensity was increased with an increase in the temperature. However, the intensity of phosphor was rapidly decreased, when HAp was appeared above $180^{\circ} \mathrm{C}$.

Furthermore, Figure 6 showed scanning electron microscopic photographs of synthesized phosphor. The shape of synthesis phosphor was aggregation of small plate-like about $1 \mu \mathrm{m}$ crystals at $120^{\circ} \mathrm{C}(\mathrm{a})$. The particle size was increased with an increase in the

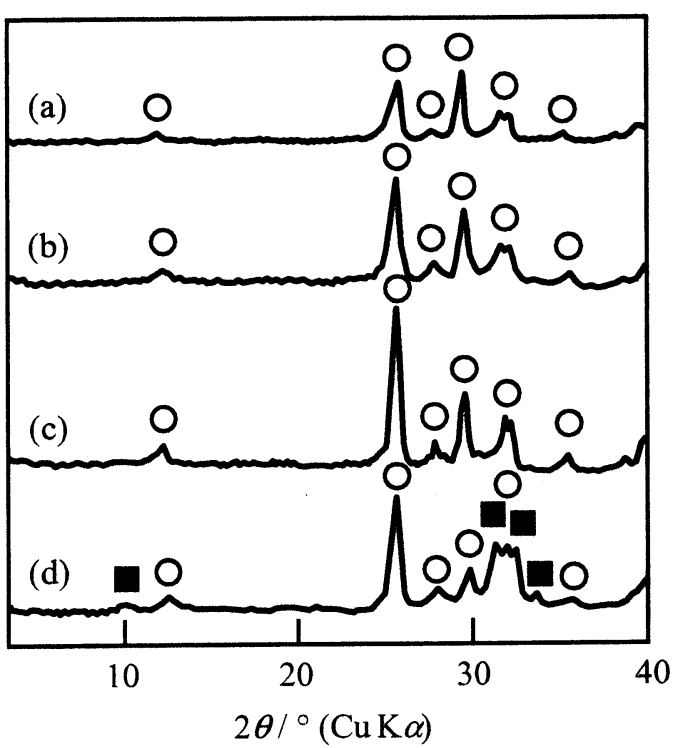

Fig.4 X-ray diffraction pattern of phosphor in comparison to hydrothermal temperature.

Retention time: $0 \mathrm{~h}$, Concentration of formic acid: 1.0 $\mathrm{mol} \cdot \mathrm{dm}^{-3}, \mathrm{Ce} / \mathrm{Ca}$ atomic ratio: 0.01 , Temp. $\left({ }^{\circ} \mathrm{C}\right),(\mathrm{a})$ : 120, (b): 150, (c): 170, (d): 200

O: $\mathrm{CaHPO}_{4}, \mathbf{H A p}$

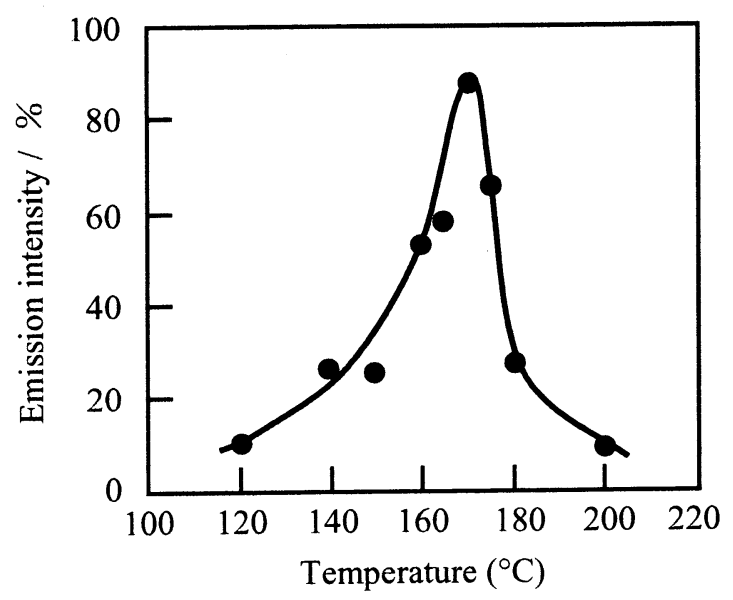

Fig.5 Effect of hydrothermal temperature on the emission intensity of $\mathrm{CaHPO}_{4}: \mathrm{Ce}^{3+}$ phosphor.

Retention time: $0 \mathrm{~h}$, Concentration of formic acid: 1.0 $\mathrm{mol} \cdot \mathrm{dm}^{-3}, \mathrm{Ce} / \mathrm{Ca}$ atomic ratio: 0.01 , Excitation wavelength: $320 \mathrm{~nm}$, Measuring wavelength: $370 \mathrm{~nm}$

temperature(b). When the emission intensity of phosphor was the greatest at $170^{\circ} \mathrm{C}(\mathrm{c})$, the shape was plate-like about $20-30 \mu \mathrm{m}$ in length, $3 \mu \mathrm{m}$ in thick. Also, the shape of this $\mathrm{CaHPO}_{4}: \mathrm{Ce}^{3+}$ phosphor was superior to high spredability. But above $200^{\circ} \mathrm{C}(\mathrm{d})$, HAp was observed with needle-like crystal having $10-20 \mu \mathrm{m}$ in $\operatorname{size}(\mathrm{d})$. 

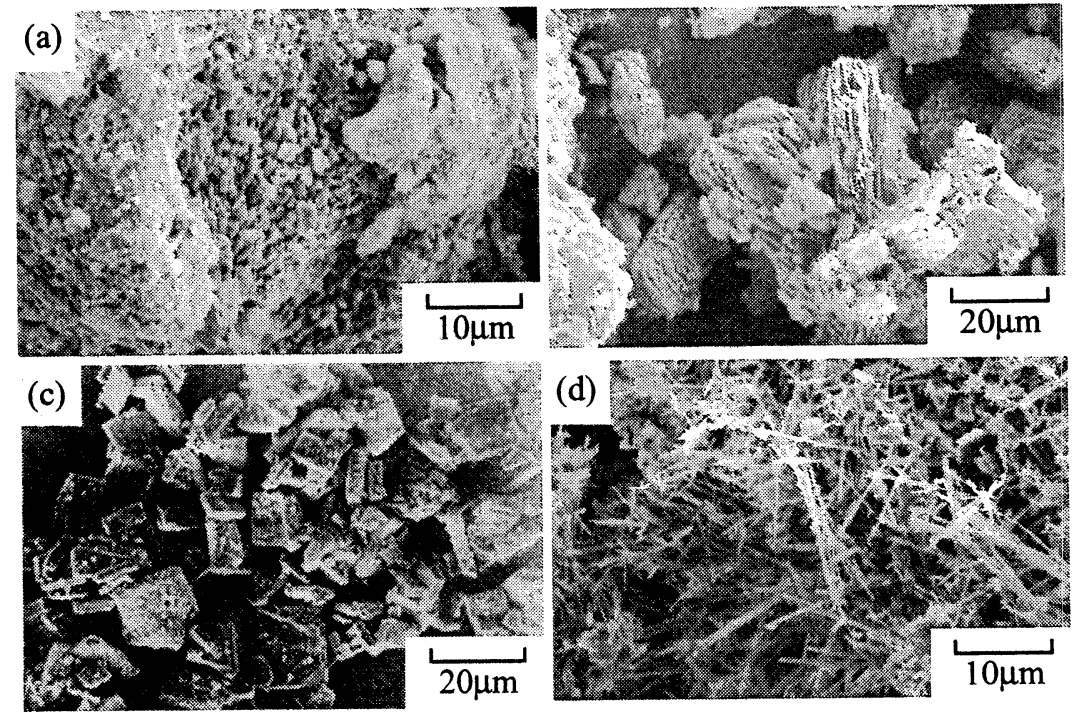

Fig.6 Scanning electron microscopic photograph of $\mathrm{CaHPO}_{4}: \mathrm{Ce}^{3+}$ phosphor in comparison to hydrothermal temperature.

Retention time: $0 \mathrm{~h}$, Concentration of formic acid: $1.0 \mathrm{~mol} \cdot \mathrm{dm}^{-3}, \mathrm{Ce} / \mathrm{Ca}$ atomic ratio: 0.01 , Temp. $\left({ }^{\circ} \mathrm{C}\right)$, (a): $120,($ b): $150,(c): 170,(d): 200$

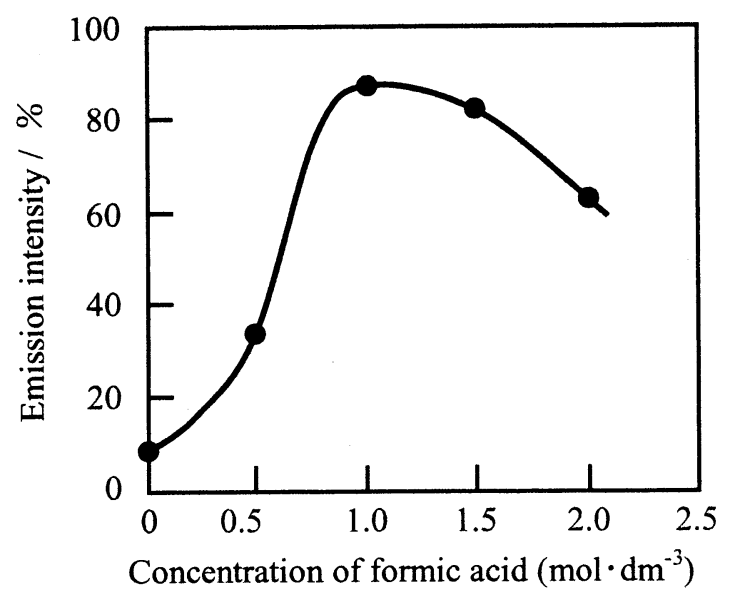

Fig.7 Effect of concentration of formic acid on the emission intensity of $\mathrm{CaHPO}_{4}: \mathrm{Ce}^{3+}$ phosphor.

Temp.: $170^{\circ} \mathrm{C}$, Retention time: $0 \mathrm{~h}, \mathrm{Ce} / \mathrm{Ca}$ atomic ratio: 0.01 , Excitation wavelength: $320 \mathrm{~nm}$, Measuring wave- length: $370 \mathrm{~nm}$.

Figure 7 showed the effect of concentration of formic acid on the emission intensity of $\mathrm{CaHPO}_{4}: \mathrm{Ce}^{3+}$ phosphor. The emission of phosphor was little observed without adding formic acid. The emission intensity was increased with an increase in the concentration of formic acid. However, the intensity was gradually decreased at the concentration of formic acid above $1.0 \mathrm{~mol} \cdot \mathrm{dm}^{-3}$. The result was suggested

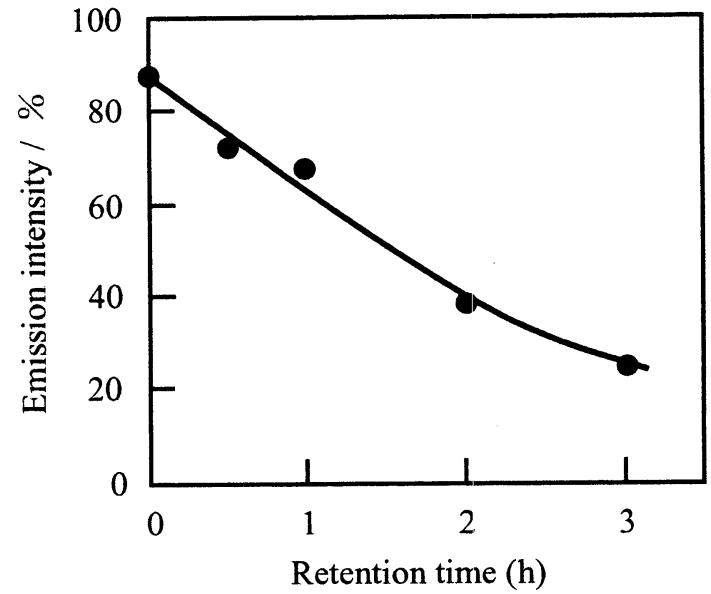

Fig.8 Effect of hydrothermal time on the emission intensity of $\mathrm{CaHPO}_{4}: \mathrm{Ce}^{3+}$ phosphor.

Temp.: $170^{\circ} \mathrm{C}$, Concentration of formic acid: $1.0 \mathrm{~mol}$. $\mathrm{dm}^{-3}, \mathrm{Ce} / \mathrm{Ca}$ atomic ratio: 0.01 , Excitation wavelength: $320 \mathrm{~nm}$, Measuring wavelength: $570 \mathrm{~nm}$.

that the phosphor was dissolved into formic acid with high concentration having lower $\mathrm{pH}$.

Figure 8 showed the effect of hydrothermal time on the emission intensity of $\mathrm{CaHPO}_{4}: \mathrm{Ce}^{3+}$ phosphor. In the course of this process, the emission intensity was showed the maximum of $90 \%$. However, the emission intensity was decreased with an increase in the hydrothermal time. It was confirmed that the 


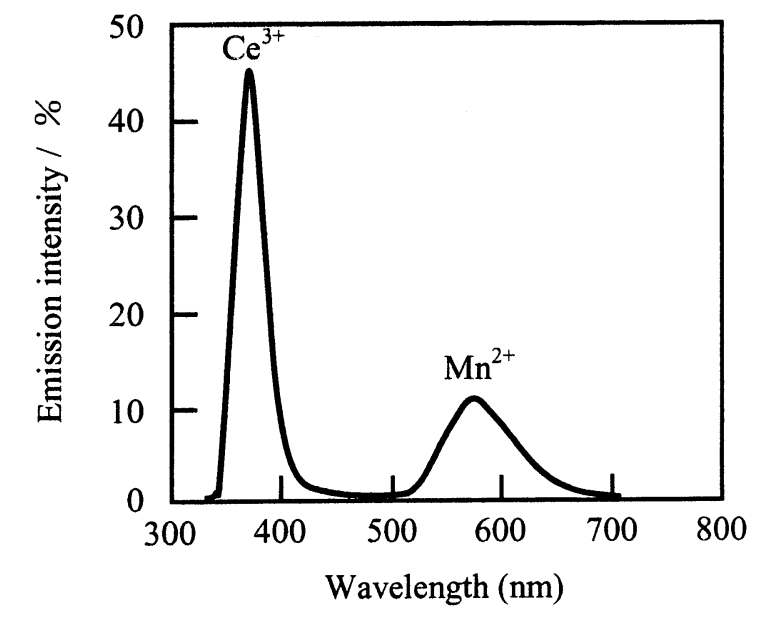

Fig.9 Emission spectrum of $\mathrm{CaHPO}_{4}: \mathrm{Ce}^{3+}, \mathrm{Mn}^{2+}$ phosphor.

Temp.: $170^{\circ} \mathrm{C}$, Retention time: $0 \mathrm{~h}$, Concentration of formic acid: $1.0 \mathrm{~mol} \cdot \mathrm{dm}^{-3}, \mathrm{Ce} / \mathrm{Ca}$ atomic ratio: 0.01 , $\mathrm{Mn} / \mathrm{Ca}$ atomic ratio: 0.02 , Excitation wavelength: 320 $\mathrm{nm}$.

crystalline of $\mathrm{CaHPO}_{4}: \mathrm{Ce}^{3+}$ phosphor which was synthesized at once was decreased, when the phosphor was dipped in formic acid solution with strong acid about $\mathrm{pH} 2$ for a long time.

\section{PREPARATION CONDITION OF CERIUM(III), MANGANGE(II) ACTIVATED DCPA PHOSPHOR}

It is luminescence of $\mathrm{CaHPO}_{4}: \mathrm{Ce}^{3+}$ phosphor can not be confirmed by human eye, because the luminescence is UV region of $370 \mathrm{~nm}$. However, $\mathrm{Mn}^{2+}$ was newly activated to $\mathrm{CaHPO}_{4}: \mathrm{Ce}^{3+}$ phosphor, energy transfer from $\mathrm{Ce}^{3+}$ to $\mathrm{Mn}^{2+}$ is induced, and it is expected that the orange-red emission would be observed.

Therefore, Figure 9 showed the emission spectrum of $\mathrm{CaHPO}_{4}: \mathrm{Ce}^{3+}, \mathrm{Mn}^{2+}$ phosphor with the most suitable condition. It was observed that the phosphor was emitted the near-UV of $\mathrm{Ce}^{3+}$ at $370 \mathrm{~nm}$ and orange light of $\mathrm{Mn}^{2+}$ at $575 \mathrm{~nm}$ under conditions of black light irradiation at $320 \mathrm{~nm}$. The phosphor of visible light emitting was able to produce by $\mathrm{Ce}^{3+}$ and $\mathrm{Mn}^{2+}$ activated with DCPA host.

Figure 10 showed the effect of $\mathrm{Mn} / \mathrm{Ca}$ atomic ratio on the emission intensity of $\mathrm{CaHPO}_{4}: \mathrm{Ce}^{3+}, \mathrm{Mn}^{2+}$ phosphor. The emission intensity of $\mathrm{Ce}^{3+}$, which observed at $370 \mathrm{~nm}$, was decreased with an increase in $\mathrm{Mn} / \mathrm{Ca}$ atomic ratio. According to this, it is confirmed that $\mathrm{Ce}^{3+}$ is working effectively as a sensitizer for $\mathrm{Mn}^{2+}$. The intensity of $\mathrm{Mn}^{2+}$, which was observed at $575 \mathrm{~nm}$, was increased with an increase in the $\mathrm{Mn} / \mathrm{Ca}$ atomic ratio. The intensity of phosphor with the $\mathrm{Mn} / \mathrm{Ca}$ atomic ratio of 0.02 was showed the maximum of $12 \%$. However, the intensity was decreased at the ratio above 0.02 . The

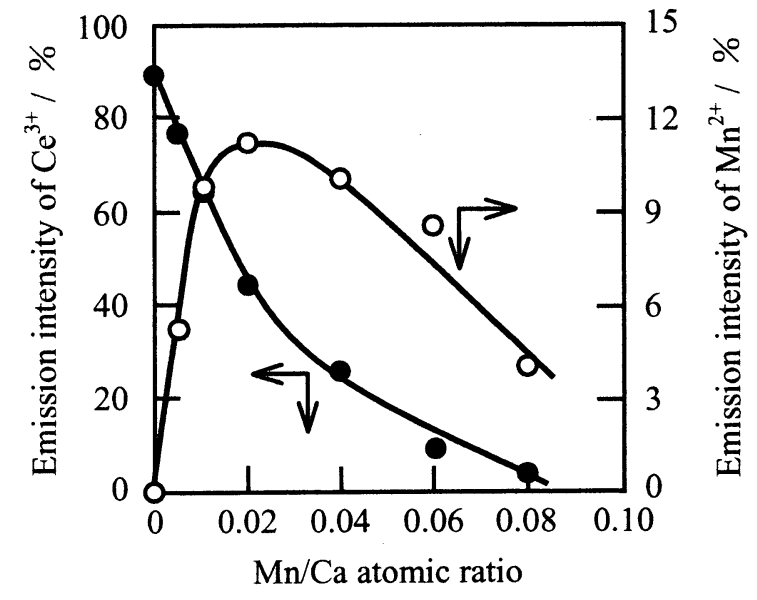

Fig.10 Effect of $\mathrm{Mn} / \mathrm{Ca}$ atomic ratio on the emission intensity of $\mathrm{CaHPO}_{4}: \mathrm{Ce}^{3+}, \mathrm{Mn}^{2+}$ phosphor.

Temp.: $170^{\circ} \mathrm{C}$, Retention time: $0 \mathrm{~h}$, Concentration of formic acid: $1.0 \mathrm{~mol} \cdot \mathrm{dm}^{-3}, \mathrm{Ce} / \mathrm{Ca}$ atomic ratio: 0.01 , Excitation wavelength: $320 \mathrm{~nm}$, Measuring wavelength: $370,570 \mathrm{~nm}$.

reason is considered that an increasing in the amount of incorporation of $\mathrm{Mn}^{2+}$ is caused a concentration quench.

The chemical formula of DCPA phosphor was quantified as $\mathrm{Ca}_{0.949} \mathrm{Ce}_{0.016} \mathrm{Mn}_{0.027} \mathrm{HPO}_{4}$ by chemical analysis.

\section{SUMMARY}

Generally, the synthesis of phosphor was produced on under conditions of the dry process with the high temperature above $1000^{\circ} \mathrm{C}$. In this study, it was possible that activator of $\mathrm{Ce}^{3+}$ and $\mathrm{Mn}^{2+}$ was incorporation into DCPA host by using active $\mathrm{ACP}$ as starting material, in spite of wet process. Also, the activated DCPA was a new unprecedented phosphor. This phosphor was emitted the orange light at $570 \mathrm{~nm}$ by the near-UV irradiation at $320 \mathrm{~nm}$. The shape of $\mathrm{CaHPO}_{4}: \mathrm{Ce}^{3+}, \mathrm{Mn}^{2+}$ phosphor was plate-like, and it was superior to high sparedabily.

The authors would like to express their thanks to Takeshi SAITOH and Arata HIGASHIGUCHI of the student of Nihon University, Faculty of Science and Engineering, for their enthusiastic cooperation.

\section{REFERENCES}

1. K. H. Butler, C. W. Jerome, J. Electrochem. Soc., 97, 265 (1950).

2. S. T. Henderson, P. W. Ranby, J. Electrochem. Soc., 104, 10 (1957). 
Toyama T, Hashimoto M, Kojima T, Yasue T

3. H. C. Froelich, J. M. Margolis, J. Electrochem. Soc., 98, 400 (1951).

4. S. Shionoya, W. M. Yen, Phosphor Handbook (CRC Press, Boca Raton, 1998), p.396.

5. T. Yasue, A. Yoshiyama, Y. Arai, Phos. Res. Bull., 1, 27 (1991).

6. T. Yasue, K. Kojima, A. Yoshiyama, Y. Arai, Phos. Sulf. Silicon, 77, 290 (1993).

7. T. Yasue, Y. Arai, J. Inorg. Mater. Soc. Japan (Gypsum \& Lime), No.243, 108 (1993).

8. Y. Kojima, K. Sakama, T. Toyama, T. Yasue, Y. Arai, Phos. Res. Bull., 4, 47 (1994).

9. T. Yasue, K. Masuda, Y. Kojima, Y. Arai, J. Ceram. Soc. Japan, 102, 1122 (1994).

10. Y. Kojima, Y. Yamamoto, T. Yasue, Y. Arai, Phos. Res. Bull., 5, 59 (1995).

11. Y. Kojima, T. Yaue, Y. Arai, Phos. Res. Bull., 6, 313 (1996).

12. T. Toyama, T. Yasue, Y. Arai , J. Ceram. Soc. Japan, 105, 976 (1997).

13. Y. Kojima, T. Hayashi, T. Yasue, Y. Arai, Phos. Res. Bull., 8, 59 (1998).

14. T. Toyama, T.Yasue, Y.Arai, Phos. Res. Bull., 8, 65 (1998).

15. T. Toyama, T.Yasue, Y.Arai, J. Ceram. Soc. Japan, 106, 984 (1998).
16. T. Yasue, Phos. Lett., 32, 5 (1998).

17. T. Toyama, S. Motoki, T. Yasue, Y. Arai, J. Inorg. Mater. Soc. Japan (Muki-materiaru), 5, 314 (1998).

18. T. Toyama, T. Dokushima, T. Yasue, Y. Arai, $J$. Inorg. Mater. Soc. Japan (Muki-materiaru), 5, 479 (1998).

19. T. Yasue, T. Toyama, Y. Arai, J. Inorg. Mater. Soc. Japan (Muki-materiaru), 6, 336 (1999).

20. T. Toyama, K. Misawa, T. Yasue, Y. Arai, J. Inorg. Mater. Soc. Japan, 7, 19 (2000).

21. T. Toyama, A. Oshima, T. Yasue, J. Ceram. Soc. Japan, 109, 232 (2001).

22. T. Toyama, K. Nakashima, T. Yasue, J. Ceram. Soc. Japan, 110, 716 (2002).

23. T. Toyama, S. Ishikawa, T. Yasue, J. Soc. Inorg. Mater. Japan, 11, 19 (2004).

24. T. Kojima, T. Toyama, T. Yasue, Y. Arai, " $14^{\text {th }}$ Ceramics Research Conference of Kanto Branch", (1998)p.37.

25. J.C.Elliott, Structure and Chemistry of the Apatites and Other Calcium Orthophosphate (Elsevier, Amsterdam, 1994), p.29. 